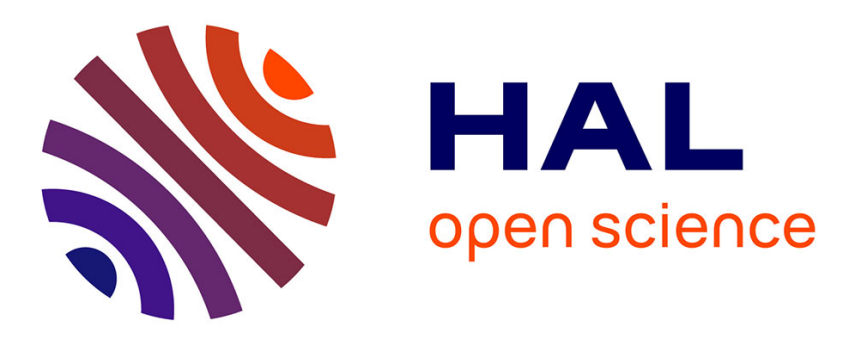

\title{
Increasing the spatial resolution of gridded data by fusion with other data sets
}

Lucien Wald, Thierry Ranchin, Mireille Lefèvre, Michel Albuisson, Jan

Remund

\section{- To cite this version:}

Lucien Wald, Thierry Ranchin, Mireille Lefèvre, Michel Albuisson, Jan Remund. Increasing the spatial resolution of gridded data by fusion with other data sets. 6th International Conference on Information Fusion, Jul 2003, Cairns, Australia. pp.168-173. hal-00395028

\section{HAL Id: hal-00395028 \\ https://hal.science/hal-00395028}

Submitted on 14 Jun 2009

HAL is a multi-disciplinary open access archive for the deposit and dissemination of scientific research documents, whether they are published or not. The documents may come from teaching and research institutions in France or abroad, or from public or private research centers.
L'archive ouverte pluridisciplinaire HAL, est destinée au dépôt et à la diffusion de documents scientifiques de niveau recherche, publiés ou non, émanant des établissements d'enseignement et de recherche français ou étrangers, des laboratoires publics ou privés. 


\title{
Increasing the Spatial Resolution of Gridded Data by Fusion with Other Data Sets
}

\author{
Lucien Wald (1), Thierry Ranchin (1), Mireille Lefèvre (1), Michel Albuisson (1), Jan Remund (2) \\ (1) Ecole des Mines de Paris, BP 207, 06904 Sophia Antipolis, France, lucien.wald@ensmp.fr
}

(2) Meteotest, Fabrikstrasse 14, 3012 Bern, Switzerland

\begin{abstract}
A method is proposed for increasing the spatial resolution of gridded data with a special emphasis in climatology. Given a set of gridded data at low spatial resolution, and assuming the existence of other data sets at better resolutions, the method takes advantage of these additional information. It extracts the high frequencies from the other sets, infers the searched high frequencies from these and performs a synthesis of the initial data at the better resolution available in the data sets. The method is explained in the general case. An application is performed that aims at synthesizing worldwide maps of climatological values of the atmospheric optical turbidity at a resolution of 5', starting from an initial resolution of $160^{\prime}$ of arc angle.
\end{abstract}

Keywords: Image processing, geo-information, image fusion, multiresolution, climatology, ARSIS concept.

\section{Introduction}

Gridded data in environment often result from application of numerical models (e.g., weather models) or processing of satellite images. Examples are climatological maps of geophysical parameters, e.g., air temperature.

Such maps usually exhibit very large cell sizes, of order of $1^{\circ}$ of arc angle. There is a need to increase their spatial resolution for further processing. One example is the need to obtain a cell size close to the spatial representation obtained by standard meteorological instruments at ground level, i.e. 5' of arc angle. It then permits to fuse ground measurements and gridded data, especially to correct for bias observed in gridded data [1, 2].

The problem is that such climatological maps only exist at low spatial resolution. A resampling of the maps at a finer cell size does not actually increases the spatial resolution of the data since no additional knowledge is brought. Taking advantage of the availability of other data sets of relevance to the parameter under concern, though different, a method is proposed for the synthesis of the initial gridded data at a higher resolution by the means of a fusion process.

\section{Problem statement}

Be a set of gridded data $S(0)_{\mathrm{r} 0}$ available at a spatial resolution $r 0$ (taken here as equivalent to the cell size). $S(0)$ may be multi-modality. Let be other sets of gridded data $S(\mathrm{i})_{\mathrm{r}}, \mathrm{i}=1 . . \mathrm{N}$, exhibiting spatial resolution $r i$. The sets $S(\mathrm{i})$ are ranked by decreasing cell sizes, $r N$ is the smallest cell size (the highest spatial resolution). The sets $S$ (i) can be multi-modality.

It is assumed that $S(\mathrm{i})$ and $S(0)$ are geometrically aligned. It is further assumed that each $S(\mathrm{i})_{\mathrm{r}}$ can be associated to $S(0)_{\text {r }}$, that is a relation exists between these data sets for a given resolution $r$.

The problem is the synthesis of $S(0)_{\mathrm{r} N}$.

\section{The ARSIS concept and the general solution}

The application of the ARSIS concept is one solution to this problem. The acronym ARSIS stands for the French "Amélioration de la Résolution Spatiale par Injection de Structures", which means "spatial resolution enhancement by injection of structures" $[3,4,5]$.

Under this concept, it is considered that the missing knowledge permitting to synthesize $S(0)_{\mathrm{RN}}$ from $S(0)_{\mathrm{r} 0}$, is composed of the spatial high-frequencies (formally, wavevectors) of $S(0)$ comprised between [1/(2 r0), $1 /(2 \mathrm{rN})]$. This range of high frequencies (noted HF) is present in the other data sets, e.g., $S(\mathrm{i})$ exhibits frequencies in $[1 /(2 \mathrm{r} 0)$, $1 /(2$ ri)]. An appropriate modeling permits to synthesize the searched $S(0) H F$ from the known $S(\mathrm{i}) H F$. Then the application of a multi-scale model (MSM) constructs $S(0)_{\mathrm{rN}}$, starting from $S(0)_{\mathrm{r} 0}$ and using the estimated HF.

\section{Assessing S(0)HF}

$S(0)_{\mathrm{r} 0}$ does not exhibit frequencies greater than $1 /(2 \mathrm{r} 0)$ :

$$
S(0) H F_{\mathrm{r}}=0 \text {, for } \mathrm{r}<\mathrm{r} 0
$$

Let note the multi-scale analysis process MSM. The couple of information $\left(S(\mathrm{i})_{\mathrm{r} 0}, S(\mathrm{i}) H F_{\mathrm{r} 0-\mathrm{ri}}\right)$ made of the approximation of $S(\mathrm{i})$ at resolution $r O$ and of the high frequencies of $S(\mathrm{i})$ in $[1 /(2 \mathrm{r} 0), 1 /(2 \mathrm{ri})]$ is obtained by applying the MSM to the data set $S(\mathrm{i})_{\mathrm{ri}}$ : 


$$
\left(S(\mathrm{i})_{\mathrm{r} 0}, S(\mathrm{i}) H F_{\mathrm{r} 0-\mathrm{ri}}\right)=\operatorname{MSM}\left(S(\mathrm{i})_{\mathrm{ri}}\right)
$$

The MSM process may be the multi-resolution analysis algorithm of Mallat [6] or Dutilleux [7, 8] or the generalized Laplacian pyramid [9]. The MSM process is invertible and the synthesis process is noted $\mathrm{MSM}^{-1}$

$$
S(\mathrm{i})_{\mathrm{ri}}=\operatorname{MSM}^{-1}\left(S(\mathrm{i})_{\mathrm{r} 0}, S(\mathrm{i}) H F_{\mathrm{r} 0-\mathrm{ri}}\right)
$$

Assume that:

$$
S(0)_{\mathrm{r} 0}=\mathrm{F}_{0}\left(S(\mathrm{i})_{\mathrm{r} 0}\right)+\varepsilon_{0}
$$

where $\mathrm{F}_{0}$ and $\varepsilon_{0}$ are known, e.g., by statistical regression. Note $\operatorname{var}(0)$ the fraction of variance in $S(0)_{\mathrm{r} 0}$ explained by $\mathrm{F}_{0}\left(S(\mathrm{i})_{\mathrm{r} 0}\right)$. If we write

$$
S(0)_{\mathrm{r} 1} *=\mathrm{MSM}^{-1}\left[S(0)_{\mathrm{r} 0}, \operatorname{var}(0) F_{0}\left(S(\mathrm{i}) H F_{\mathrm{r} 0-\mathrm{r} 1}\right)\right]
$$

where $S(\mathrm{i}) H F_{\mathrm{r} 0-\mathrm{r} 1}$ is obtained by applying MSM to $S(\mathrm{i})_{\mathrm{r}}$, $S(0)_{\mathrm{r} 1} *$ is an estimation of $S(0)_{\mathrm{r} 1}$.

Because the model $F_{0}$ is not exact and was assessed at another resolution $r 0$ while applied to the interval [r1, r0],

$$
\left(S(0)_{\mathrm{r} 0} *, S(0) H F_{\mathrm{r} 0-\mathrm{r} 1}^{*}\right)=\operatorname{MSM}\left(S(0)_{\mathrm{r} 1} *\right)
$$

$S(0)_{\mathrm{r} 0}$ * is not equal to $S(0)_{\mathrm{r} 0}$. It should be because the fused product should be identical to the initial product at resolution $r 0$. One corrects for it by writing:

$$
S(0)_{\mathrm{r} 1}=\operatorname{MSM}^{-1}\left(S(0)_{\mathrm{r} 0}, S(0) H F^{*}{ }_{\mathrm{r} 0-\mathrm{r} 1}\right)
$$

The process is iterated. At each step and resolution $r i$, are used the sources of data $S$ (i) having a better resolution than $r i$

At the end of the process, $S(0)_{\mathrm{rN}}$ is obtained that is an approximation of the true but unknown gridded data. In any case, this set better represents the reality than what can be obtained by a resampling of $S(0)_{\mathrm{r} 0}$.

\section{Application case}

The amount of solar radiation available at ground level for clear skies can be modeled by the means of the Linke turbidity factor, a quantity characterizing the optical turbidity of the atmosphere. There is a need for world climatological maps of the Linke turbidity factor (TL) with a cell size of 5' (approx. $10 \mathrm{~km}$ at mid-latitude).

Gridded data are available that report monthly clear sky irradiations (Staylor approximation). They are supplied by the NASA-Langley Research Center, in the framework of the Solar Radiation Budget Project SRB [10, 11]. From these data, the TL can be computed [12].

The cell is an equal area cell everywhere of $280 \times 280 \mathrm{~km}^{2}$. At mid-latitude, it corresponds to approximately $2.5 \times 2.5$ degrees $^{2}$ of arc angle. The twelve maps (one per month) of TL were re-mapped using the canonical projection. This is performed by the means of the spline bi-cubic operator. A mirror technique is used for the edges. The cells are squared and have a size of $160^{\prime}$ of arc angle. This initial set of maps is called the set $\mathrm{TL}_{\mathrm{SRB}}$ (Fig. 1).

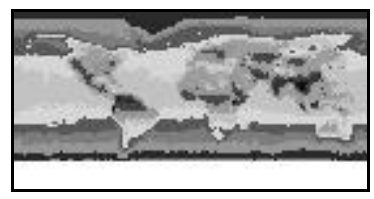

Figure 1. The set $\mathrm{TL}_{\mathrm{SRB}}$ at resolution 160 '. June. The first line is latitude $90 \mathrm{~N}$, the last is $90 \mathrm{~S}$. The first column is longitude $180 \mathrm{~W}$, the last is $180 \mathrm{E}$.

The atmospheric turbidity is a function of the amount of water vapor in the atmosphere. Within the NVAP (NASA Water Vapor Project), the NASA Langley Research Center Atmospheric Sciences Data Center combined several observations to construct world-wide maps of the content of water vapor integrated over the total column [13]. The gridded data are available on the Internet [14]. The monthly mean value for each cell over the 10 years (198897) is computed (Fig. 2).

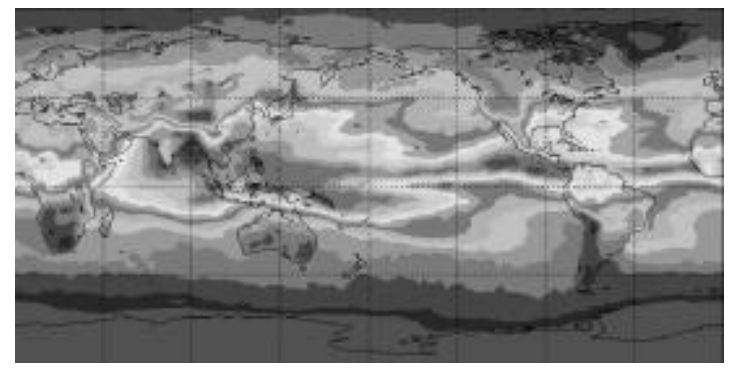

Figure 2. The map of water vapor amount for June.

The NVAP maps are re-mapped as above. The cells are squared and have a size of $80^{\prime}$ of arc angle. The relation between TL $\mathrm{LRB}_{\mathrm{SRB}}$ and NVAP (in $\mathrm{mm}$ ) was assessed over land at resolution 160' by linear regression (Table 1):

$$
T L_{S R B}=a \ln N V A P+b
$$

Table 1. Parameters of Eq. 8

\begin{tabular}{|l|c|c|}
\cline { 2 - 3 } \multicolumn{1}{c|}{} & $a$ & $b$ \\
\hline Jan & 30.7235 & -33.3767 \\
\hline Feb & 31.312 & -32.0650 \\
\hline Mar & 26.8757 & -13.3799 \\
\hline Apr & 14.8917 & 35.4049 \\
\hline May & 3.3993 & 82.0606 \\
\hline Jun & 31.7095 & -32.5927 \\
\hline
\end{tabular}

\begin{tabular}{|l|c|c|}
\cline { 2 - 3 } \multicolumn{1}{c|}{} & $a$ & $b$ \\
\hline Jul & 35.4256 & -45.4808 \\
\hline Aug & -14.3931 & 152.9660 \\
\hline Sep & 5.0209 & 78.3512 \\
\hline Oct & 13.9920 & 37.5755 \\
\hline Nov & 25.1935 & -10.5575 \\
\hline Dec & 33.1209 & -42.3625 \\
\hline
\end{tabular}

This data set NVAP is used for resolutions comprised between $80^{\prime}$ and 160' over land.

The third data set $\mathrm{TL}_{\mathrm{TMAP}}$ is composed of maps of the TL, over the oceans only. They are computed from the maps of aerosol optical depth at $630 \mu \mathrm{m}$ for several years (1985-99) found on the Web server of the Thermal Modeling and Analysis Project (TMAP) at NOAA Pacific Marine Environmental Laboratory [15]. The twelve maps were re-mapped as above. The cells are squared and have a size of $80^{\prime}$ of arc angle. This data set is used for resolutions $80^{\prime}$ to 160 ' over the oceans.

The fourth data set is a worldwide digital terrain model with a cell size of $5^{\prime}$ (Fig. 3, shown at 20' for the sake of space) [16]. This data set is used from resolution 5' to 80'. 
By application of the method described above, one obtains twelve maps of the parameter TL with a cell size of 5' (Fig. 4, shown at 20'). Here, we used the MSM of [8].

\section{Conclusions}

The ARSIS concept has mostly been used with images at high or very high spatial resolution. The present study demonstrates its potentials in climatology. By the means of a fusion process, it has been possible to synthesize climatological maps of the atmospheric turbidity at a much finer resolution than the initial one.

The standard implementations of the ARSIS concept, and especially the Inter-Modality Models (IMM), apply to the high frequencies $[4,5]$. Here, the IMM is assessed on the approximations themselves; the HRIMM (High Resolution IMM) is applied on the high frequencies.

Another innovation in this implementation is its iterative process: at each resolution, two synthesis are performed. They are separated by an analysis process and a substitution of the analysis results by the fused product obtained at the previous resolution. In current implementations, the HRIMM replicates the model IMM and comprises only one synthesis. This approach was selected here to ensure that i) the fused product is equal to the initial one once resampled to the initial resolution and ii) the intensity of injected high frequencies is reasonable in order to avoid spatial artifacts.

\section{References}

[1] Hans-Georg Beyer, G. Czeplak, U. Terzenbach, and L. Wald, 1997. Assessment of the method used to construct clearness index maps for the new European solar radiation atlas (ESRA). Solar Energy, Vol. 61, No. 6, pp. 389-397, 1997.

[2] Vittorio D'Agostino, and A. Zelenka, Estimating solar global irradiance by integration of satellite and network data: the cokriging approach, Sciences de la Terre, Sér. Inf., Vol. 31, pp. 461-465, 1992.

[3] Thierry Ranchin, and L. Wald, Fusion of high spatial and spectral resolution images: the ARSIS concept and its implementation, Photogrammetric Engineering and Remote Sensing, Vol. 66, No. 1, pp. 49-61, 2000.

[4] Lucien Wald, Data Fusion. Definitions and Architectures - Fusion of Images of Different Spatial Resolutions, Les Presses de l'Ecole des Mines de Paris, Paris, France, 198 p., 2002.

[5] Thierry Ranchin, B. Aiazzi, L. Alparone, S. Baronti, and L. Wald, Fusion of images for urban areas studies. The ARSIS concept and some successful implementation schemes, To appear in ISPRS Journal of Photogrammetry \& Remote Sensing, 2003.
[6] S. G. Mallat, A theory for multiresolution signal decomposition: the wavelet representation, IEEE Transactions on Pattern Analysis and Machine Intelligence, Vol. 11, No. 7, pp. 674-693, 1989.

[7] P. Dutilleux, An implementation of the "algorithme à trous" to compute the wavelet transform, In Compterendus du congrès ondelettes et méthodes tempsfréquence et espace des phases, Marseille 14-18 septembre 1987, Springer-Verlag ed., pp. 298-304, 1987.

[8] Jean-Louis Starck, and F. Murtagh, Image restoration with noise suppression using the wavelet transform, Astronomy Astrophysics, Vol. 288, pp. 342-350, 1994.

[9] Bruno Aiazzi, L. Alparone, F. Argenti, and S. Baronti, Wavelet and pyramid techniques for multisensor data fusion: a performance comparison varying with scale ratios, In Image and Signal Processing for Remote Sensing V, S. B. Serpico, Ed., SPIE vol. 3871, pp. 251-262, 1999.

[10] R. C. DiPasquale, and C. H. Whitlock, Global distribution of shortwave fluxes derived from satellite data for the world climate research programme, International Journal of Climatology, Vol. 15, pp. 961-974, 1992.

[11] Charles H. Whitlock, First global WCRP shortwave surface radiation budget dataset, Bulletin of the American Meteorological Society, 76, 905-922, 1995.

[12] Jan Remund, L. Wald, M. Lefevre, T. Ranchin, and J. Page, Worldwide Linke turbidity information, To be presented at ISES 2003 (International Solar Energy Society), Goeteborg, Sweden, 16-19 June 2003.

[13] D. L. Randel, T. H. Vonder Haar, M. A. Ringerud, G. L. Stephens, T. J. Greenwald, and C. L. Combs, A new global water vapor dataset, Bulletin of the American Meteorological Society, Vol. 77, No 6, June 1996.

[14] NVAP - NASA Water Vapor Project. NASA Langley Research Center Atmospheric Sciences Data Center, Web site: http://eosweb.larc.nasa.gov, as of 2001.

[15] TMAP - Thermal Modeling and Analysis Project. NOAA Pacific Marine Environmental Laboratory, http://las.saa.noaa.gov/las-bin/climate_server/dset= AVHRR+PATHFINDER, as for August 2001

[16] TerrainBase: Worldwide Digital Terrain Data. Documentation Manual, CD-ROM Release 1.0, NOAA, National Geophysical Data Center, Boulder, Colorado, USA, April 1995. 


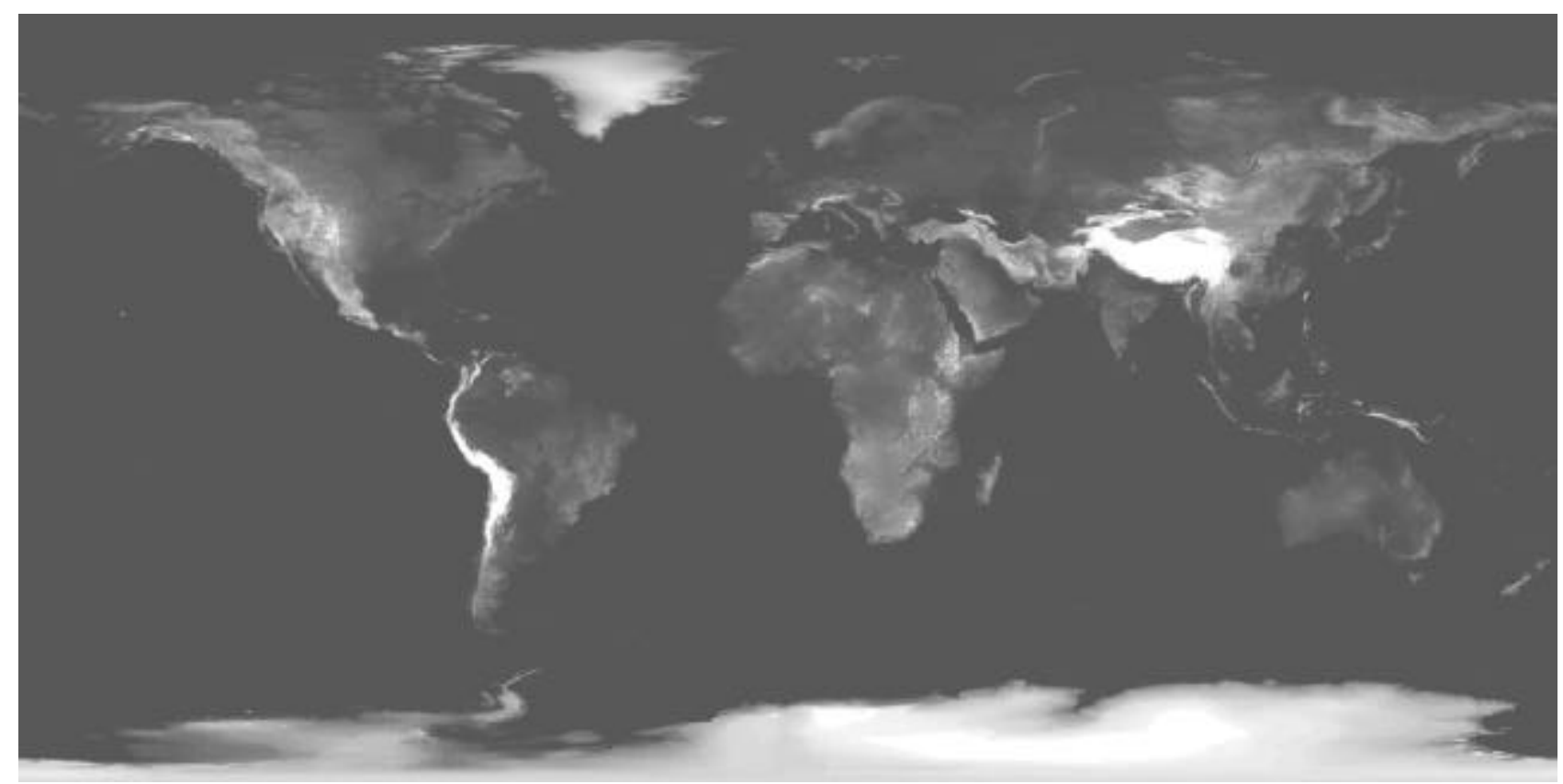

Figure 3. The digital terrain model at 20'. Black: low elevation; white: large elevation.

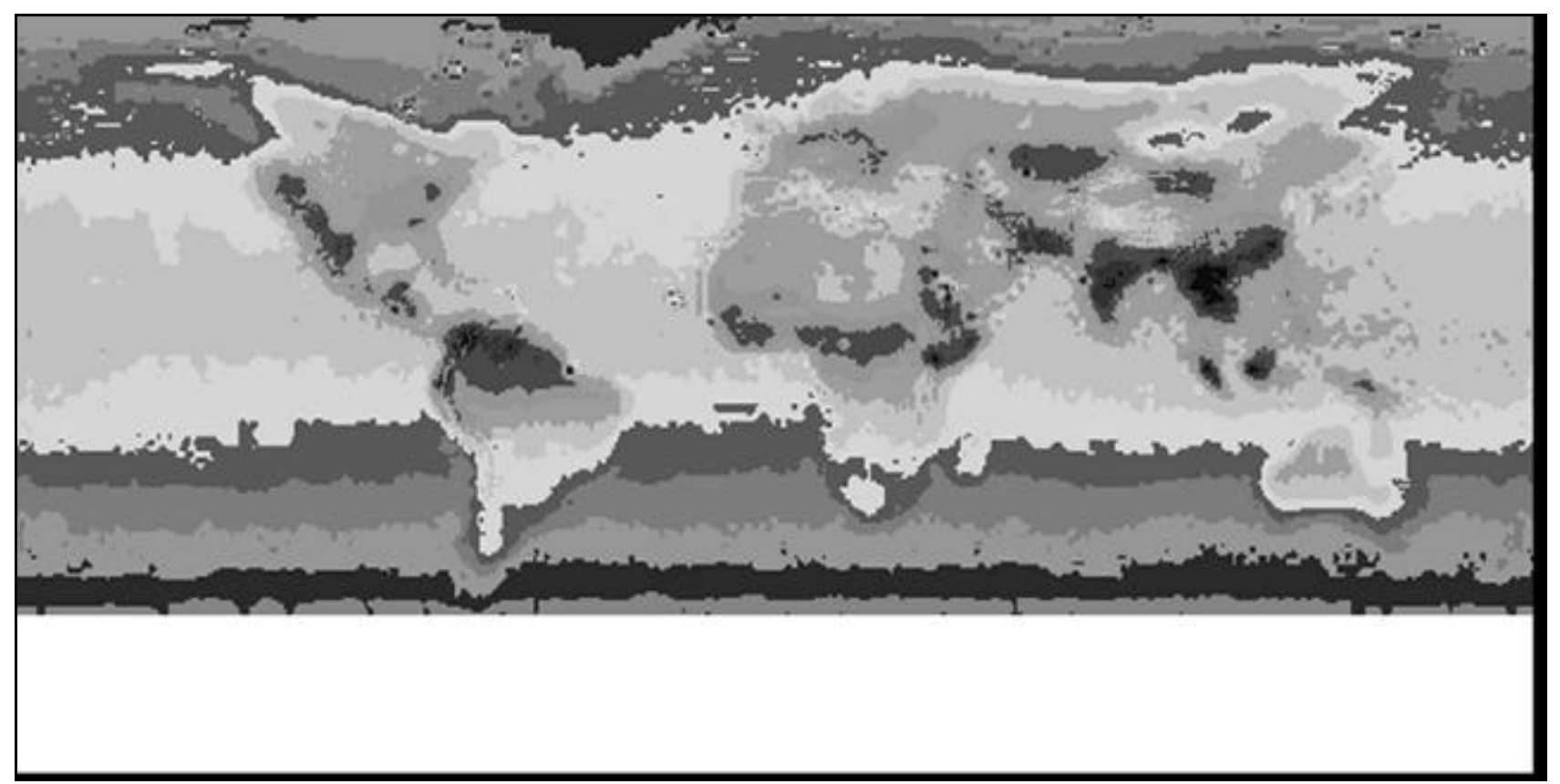

Figure 4. The synthesized map $\mathrm{TL}_{20}$ at resolution 20 ' for June. 